\title{
Science should not be left behind during the design of a marine protected area: meeting conservation priorities while integrating stakeholder interests
}

\author{
Manuel Muntoni ${ }^{\mathrm{a}}$, Rodolphe Devillers ${ }^{\mathrm{ab} \star}$, and Mariano Koen-Alonso ${ }^{\mathrm{c}}$ \\ ${ }^{a}$ Department of Geography, Memorial University of Newfoundland, St John's, NL A1B 3X9, Canada; \\ ${ }^{\mathrm{b}}$ CRIOBE, USR 3278 CNRS-EPHE-UPVD, PSL Research University, Perpignan, 66860, France; ${ }^{\mathrm{c}}$ Fisheries \\ and Oceans Canada, St John's, NL A1C 5X1, Canada \\ *rdeville@mun.ca
}

\begin{abstract}
Marine protected areas (MPAs) design is a complex process that typically involves diverse stakeholders, requiring compromise between diverging priorities. Such compromises, when not carefully understood, can threaten the ecological effectiveness of MPAs. Using the example of the Canadian Laurentian Channel MPA, we studied a planning process from initial scientific advice to the final MPA. We analysed the impacts of successive boundary modifications to the draft MPA, often made to accommodate extractive industries, on the protection of seven species initially identified as potential conservation priorities. We also quantified the potential economic impacts of changes in boundary modifications on the fisheries industry. Results show that reducing the proposed MPA size by $33.4 \%$ helped reduce the potential economic impact on the fishing industry by $65.5 \%$, but it resulted in up to $43 \%$ decrease in protection of species of conservation priority. Changes in MPA boundary delineation during the design were not subjected to formal scientific reviews, raising questions on the potential effectiveness of this MPA. Better integration of science in MPA design is required to help assess the impacts that trade-offs made during stakeholder consultations can have on the MPA ecological effectiveness.
\end{abstract}

Citation: Muntoni M, Devillers R, and KoenAlonso M. 2019. Science should not be left behind during the design of a marine protected area: meeting conservation priorities while integrating stakeholder interests. FACETS 4: 472-492. doi: I 0.1 I 39 / facets-20 I 8-0033

Handling Editor: Daniel E. Schindler

Received: August 30, 2018

Accepted: June 24, 2019

Published: September 16, 2019

Copyright: (C) 2019 Muntoni et al. This work is licensed under a Creative Commons Attribution 4.0 International License (CC BY 4.0), which permits unrestricted use, distribution, and reproduction in any medium, provided the original author(s) and source are credited.

Published by: Canadian Science Publishing

Key words: conservation planning, MPA effectiveness, science-policy interface, stakeholder consultation, trade-offs

\section{Introduction}

With a rising global population that relies on a broad range of natural resources, humans increasingly impact marine environments (Halpern et al. 2008), leading to large and rapid declines in marine biodiversity across the globe (Johnson et al. 2017). To help prevent, or at least slow down this decline, conservation actions are taking place from local to international levels. Amongst those actions, marine protected areas (MPAs) are now widely considered as the cornerstone of most national marine conservation strategies. While MPAs can result in a broad range of benefits that extend beyond nature conservation (e.g., fisheries spill-over effect, and various ecosystem services), in this paper we adopt the definition from the International Union for the Conservation of Nature that states that the primary objective of any MPA should be nature conservation. In the last decade, the number and global coverage of MPAs increased rapidly, resulting largely from commitments by nations to meet 
international conservation targets, such as the Convention on Biological Diversity Aichi targets (CBD 2011) and the United Nations sustainable development goals. This increase in the creation of new MPAs brings to light growing conflicts between society's dependence on natural resources and the need to protect nature.

While MPAs have been shown to be effective at preventing the decline of marine biodiversity, individual MPA effectiveness varies and depends on many factors that include their size, level of protection, location, and successful funding and enforcement (e.g., Edgar et al. 2014). Socio-economic criteria have been recognized as fundamental determinants in the success of MPAs (Mascia 2003). Stakeholder engagement, made possible by involving ocean users at different stages of the MPA planning process, is deemed critical to MPA design and management (Jessen et al. 2011), helping to increase the acceptance of the MPA by local stakeholders (Garcia-Charton et al. 2000; Dehens and Fanning 2018), and hence increasing stakeholders' support for the MPA (Kessler 2004; Pomeroy and Douvere 2008; Ruiz-Frau et al. 2015). Meeting conservation priorities at an acceptable socioeconomic cost is challenging (Allison et al. 1998; Devillers et al. 2015), and accommodating too many requests from stakeholders (e.g., allowing some types of activities, changing the MPA boundaries) risks compromising the MPA ability to reach its desired conservation benefits (Kessler 2004). While some MPAs successfully balance ecosystem health and human well-being, harder trade-offs are in many cases required and can lower ecological effectiveness of MPAs (Leslie and McLeod 2007). While any MPA planning involves some level of trade-offs, the question becomes at what point those compromises risk creating an MPA that would be ineffective in reaching its conservation outcomes.

Business interests, and the pressures exerted on the governance systems for resolving stakeholder concerns, have been shown in some cases to undermine MPA design process, and in turn, the effectiveness of MPAs, particularly in the case of weaker stakeholder support (Oracion et al. 2005) or low institutional capacity (Jameson et al. 2002). While the literature documents many benefits resulting from stakeholder involvement in MPA design processes (Chess and Purcell 1999; Chess 2000), negative consequences are rarely reported and should be better documented.

This study, which uses the Canadian context as an example, aims at better understanding how stakeholder involvement and management decisions guiding an MPA design process can negatively impact the conservation potential of an MPA.

MPA establishment in Canada started in 1997 with the Oceans Act legislation (Minister of Justice of Canada 1997), resulting in the creation of 13 MPAs from 2003 to 2019. Stakeholder engagement was central to the establishment of those MPAs, with some MPA design processes initiated at the request of local groups interested in protecting fish populations important to the local industry (e.g., Gilbert Bay and Eastport MPAs in the province of Newfoundland and Labrador (NL)). Under Canada's Oceans Act, sites of interest for a future MPA are first identified officially as areas of interest (AOI). Planning for those sites then follows a process that typically takes 7-8 years on average before the MPA is officially created.

We used the Laurentian Channel (LC) MPA as an example (Fig. 1), an area initially identified by a government scientific process as an ecologically and biologically significant area (EBSA), which became in 2019 one of Canada's largest MPAs. With a size of about $11619 \mathrm{~km}^{2}$, the MPA covers part of the Laurentian channel that connects the Gulf of Saint Lawrence to the Atlantic Ocean on Canada's east coast, with depths ranging from 139 to $485 \mathrm{~m}$ and a seabed largely dominated by fine sediments (DFO 2011). The LC is thought to be a nursery ground for several species, such as porbeagle shark (Lamna nasus), black dogfish (Centroscyllium fabricii), and smooth skate (Malacoraja senta). It also offers suitable habitats for sea pens (Pennatulacea) and is a migration corridor for several marine mammal species moving into and out of the Gulf of Saint Lawrence. Through an analysis of 


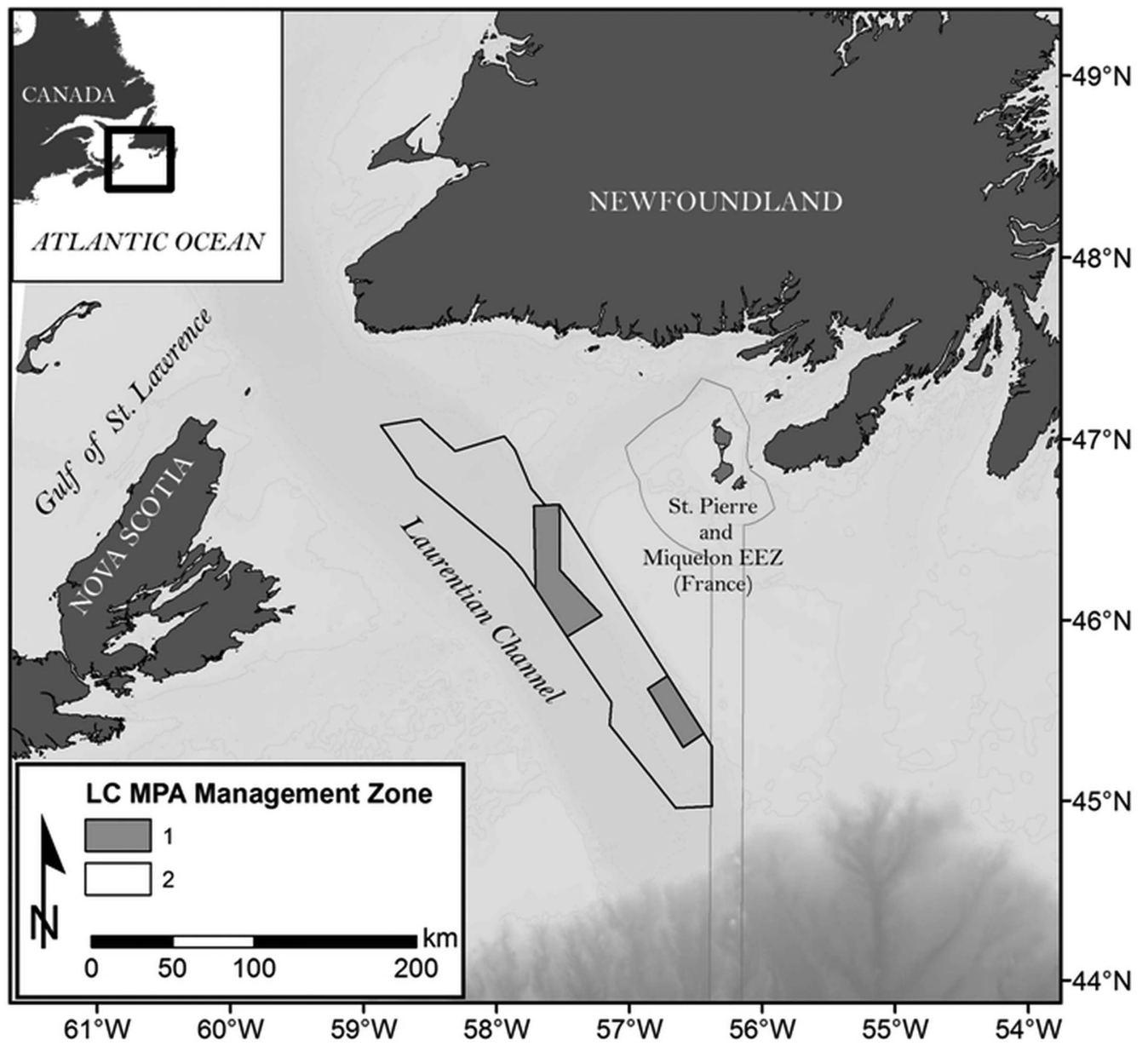

Fig. 1. Laurentian Channel (LC) marine protected area (MPA) showing the two management zones (Zone 1 offers the highest protection). St. Pierre and Miquelon's waters (France territorial waters) are also presented.

government documents and data, we explored how stakeholder engagement impacted the MPA planning process and its potential impacts on the MPA effectiveness.

\section{Material and methods}

To help reconstruct the history of the planning process for the LC MPA, we first read 17 documents produced between 2009 and 2015 by the Department of Fisheries and Oceans (DFO), the Canadian government agency in charge of designing the LC MPA (See Table S1, for a complete list of the documents). These public and internal documents (e.g., memos, presentations, reports) described various aspects of the MPA design process and helped identify specific stages where the proposed MPA boundaries were modified. Those stages were used in subsequent biological and socio-economic data analyses to understand the impact of boundary changes on species and on the fishing industry. Those documents also provided diverse information, such as reasons why changes were made to the AOI boundaries, data used to support those decisions, information on the position of various stakeholder groups with regards to the MPA planning, changes in species of conservation priority, etc. In the second part of our work, we conducted spatial analyses using government biological and socioeconomic data to quantify the impact that MPA boundary modifications had, at each stage, in terms 
Table 1. Species identified as conservation priorities for the LC MPA at different stages of the boundary delineation process.

\begin{tabular}{|c|c|c|c|}
\hline & \multicolumn{3}{|c|}{ LC MPA planning process timeline } \\
\hline & November 2011 & December 2011 & 2012 \\
\hline Basking shark & $\checkmark$ & - & - \\
\hline Black dogfish & $\checkmark$ & $\checkmark$ & $\checkmark$ \\
\hline Cetaceans & $\checkmark$ & - & - \\
\hline Cod & $\checkmark$ & $\checkmark$ & - \\
\hline Haddock & $\checkmark$ & - & - \\
\hline Leatherback turtle & $\checkmark$ & $\checkmark$ & $\checkmark$ \\
\hline Monkfish & $\checkmark$ & - & - \\
\hline Northern wolffish & $\checkmark$ & $\checkmark$ & $\checkmark$ \\
\hline Pollock & $\checkmark$ & - & - \\
\hline Porbeagle shark & $\checkmark$ & $\checkmark$ & $\checkmark$ \\
\hline Redfish & $\checkmark$ & - & - \\
\hline Sea pens ${ }^{a}$ & $\checkmark$ & $\checkmark$ & $\checkmark$ \\
\hline Smooth skate & $\checkmark$ & $\checkmark$ & $\checkmark$ \\
\hline Spiny dogfish & $\checkmark$ & $\checkmark$ & - \\
\hline Thorny skate & $\checkmark$ & - & - \\
\hline White hake & $\checkmark$ & - & - \\
\hline
\end{tabular}

Note: Checkmarks indicate species listed at the specific planning stage. LC MPA, Laurentian Channel marine protected area;

${ }^{a}$ Sea pens, together with other species, were not mentioned in the original Ecologically and Biologically Significant Area description (Templeman 2007).

of potential economic losses for the fishing industry and potential conservation losses for species of interest. Conservation losses, also identified in this paper as protection levels for the species of interest, were measured as the proportion of species abundance or biomass found outside the proposed MPA when compared to the larger original MPA boundary. This conservation loss was assessed for seven species: the five species identified in the final MPA conservation objectives and two commercial species, Atlantic cod (Gadus morhua) and redfish (Sebastes mentella), initially listed as tentative conservation objectives but removed during the process (DFO 2009).

The LC MPA was first identified as an EBSA by a scientific process in 2007 (Templeman 2007), recognizing its ecological importance for the region. Boundaries for the original LC EBSA and for the final LC MPA were provided as ArcGIS shapefiles by DFO NL Oceans Branch. Intermediate draft MPA boundaries, details on the AOI designation and the MPA planning process, and species of conservation priorities (Table 1 ) were obtained from DFO documents (See Table S1). Biological and economic data used for the analyses were provided by DFO NL Science and Oceans Branches.

\section{Biological data}

Biological data for the seven species of interest were used to estimate the abundance and biomass of each species that would be left unprotected outside of the MPA after each stage of the MPA boundary 
modification (i.e., from the larger original EBSA boundary to the smaller final MPA). Once outside, we assumed that those species were not protected anymore by the MPA and hence considered this as a conservation loss when compared to the initial EBSA boundaries delineated during a scientific process.

Abundance and biomass indices of the northern wolffish (Anarchias denticulatus), black dogfish, smooth skate, Atlantic cod, and redfish were calculated based on the DFO multispecies trawl survey database (1996-2014) for the Northwest Atlantic Fisheries Organization 3Ps and 3Pn subdivisions (spring data only). Detailed information about DFO multispecies surveys in NL waters can be found in McCallum and Walsh (1997) and NAFO (2013). Biomass index of porbeagle shark was provided by the DFO NL Science Branch, coming from fisheries observer data (1995-2012, as presented in Campana et al. 2015). Sea pens significant benthic areas (SiBAs) were obtained from the 2017 advisory process carried out by DFO Science to identify and delineate SiBAs (DFO 2017); analyses of these data provide the most up-to-date perspective regarding sea pen conservation in the LC, although most MPA design decisions involving sea pens were made based on earlier studies (i.e., DFO 2010; Kenchington et al. 2010). We did not include Leatherback sea turtles (Dermochelys coriacea) in this analysis, the last of the six final conservation objectives, on the advice this species' expert at DFO because of strong data limitations for this species that did not allow for similar quantitative analyses (Jack Lawson, personal communication).

For each stage of the MPA boundary delineation process, the total draft MPA size was calculated using Esri ArcGIS Desktop 10.3 using a Universal Transverse Mercator Zone 21 projection. The AOI was divided into $10 \mathrm{~km} \times 10 \mathrm{~km}$ grid cells, and species' abundance and (or) biomass were averaged for all available years (i.e., see above) and allocated to an individual grid cell. Cell size was selected to match other data obtained from DFO NL that were also used in this study. Average species abundance and (or) biomass were then summed for the entire original EBSA boundary and scaled to a value of 1 , representing the species abundance or biomass for each species that was included in the original EBSA boundary. Both abundance and biomass data were used as proxies to quantify potential losses in protection for the northern wolffish, black dogfish, smooth skate, cod, and redfish. Since no abundance data were available for the porbeagle shark, analyses were conducted using biomass data only. Because of differences in estimation methods, changes in sea pens protection levels were estimated by calculating the proportion of protected $\mathrm{SiBA}$ surface with respect to the surface protected within the initial EBSA boundaries. SiBA used at this stage refers to the areas identified in 2016 (Kenchington et al. 2016; DFO 2017).

We quantified decreases in species biomass and (or) abundance coverage after each MPA boundary change (i.e., each stage in the MPA planning). We then proposed three conservation loss scenarios to help interpret species loss trends. Those scenarios linked decreases in MPA size with decreases in species protection levels at each stage. A reduction in species biomass and (or) abundance that would be proportional to the reduction in size of the MPA was represented in our results by line "a" (i.e., proportional loss scenario). Under this scenario, reducing an MPA size of 30\% would for instance result in a decrease of $30 \%$ in the protection for a given species, something expected for instance if the species were distributed homogeneously in the area. Line " $b$ " (i.e., marginal loss scenario) represents a scenario where large reductions in the MPA size would only have a small impact on the species protection (adapted from Tear et al. 2005). Such a scenario, preferable for conservation, could result from removing areas from the draft MPA where species are less present. The line "c" (i.e., disproportional loss scenario) is the reverse, with small reductions in the MPA size resulting in large impact on species protection. This scenario would suggest that areas removed during the planning process included larger density of species of conservation interest. The basic underlying assumptions were that $(i)$ the original EBSA spatial extent, informed by science, provided sufficient coverage to meet the conservation objectives 
and (ii) reductions in the MPA size were mostly associated with removal of conservation objectives (i.e., species) from the process and (or) to accommodate trade-offs with different stakeholder sectors, but the reduction in size of the area did not result from a need to better match conservation objectives.

\section{Socio-economic data}

Socio-economic data were analysed to better understand the potential economic impacts each MPA planning stage could have on the fisheries industry. As the LC MPA bans all industrial fishing activities, we used past fish landing data to assess potential losses in terms of future economic opportunities for the industry. Similar to the analyses performed using biological data, we calculated decreases in the total fish landings at each stage of the MPA boundary delineation.

The mean annual fisheries landed value was calculated using $10 \mathrm{~km} \times 10 \mathrm{~km}$ gridded data provided by DFO NL Oceans Branch for the 2004-2013 period. The total economic value of the fisheries landings that have historically been generated within the proposed MPA boundaries was estimated at each stage of the boundary delineation process by summing the value of all the cells having their centroid within the proposed MPA boundary. This mean annual fisheries landed value was used to estimate the economic impact the MPA would have after a ban on industrial fishing activities in the area that would result from the creation of the MPA (including shrimp trawlers, purse seiners, potters, longliners, gill-netters, and bottom otter trawlers). Then, the Spearman correlation coefficient was calculated to assess the significance of the relationship between fisheries landed values and species protection values (i.e., abundance and (or) biomass of species within the MPA boundary) at each stage of the planning process. We designed our analyses to separately explore the species that remained conservation objectives until the end of the planning process, and two species of commercial interest (i.e., cod and redfish) that were removed from the conservation objective list during the planning process. This helped explore the premise that the boundary modification process was primarily driven by the removal of areas from the AOI characterised by high concentrations in commercial species, something also documented in the documents consulted in this study.

\section{Results}

\section{Policy context and identification of AOI}

In 2008, the Canadian government (i.e., DFO) initiated a process aiming to identify an AOI that could lead to the creation of a new MPA in the waters of NL. This process started by considering 11 areas of ecological importance-EBSAs-identified by DFO Science branch in 2007 (Templeman 2007). This phase was informed by bilateral meetings held between DFO and nine stakeholder groups and was also influenced because DFO was interested in creating a large offshore MPA that could protect marine biodiversity more broadly. This decision was influenced because the two existing MPAs in this province are small, coastal, and focus on commercial species (i.e., cod for the Gilbert Bay MPA and lobster for the Eastport MPA). This process allowed shortlisting five EBSAs as candidate AOIs. Twenty-two stakeholder groups were then formally consulted in 2008 and 2009 to help select one AOI out of those five candidates. DFO reports indicate that only four groups showed support for one or more of the five areas, 14 groups showed no preference (nor opposition) for any area, while the other groups, mostly fishing industry groups, generally opposed areas used by their members (DFO 2009). Subsequent socio-economic studies conducted by DFO identified the LC as the EBSA, out of the five candidate EBSA sites, that would result in the lowest expected foregone economic benefit if closed to industrial fishing. The average annual value of the commercial fisheries in the LC was about CAD $\$ 4.35$ million (2004-2007), compared with between CAD\$8.13 and CAD\$32.14 million for the other EBSAs (DFO 2009). Due to the lower risk of displacement of resource users, the lower potential resistance from industries related to this, and a clearer federal jurisdiction in the area, the LC EBSA was officially announced in 2010 as an AOI for a future MPA establishment. 


\section{The LC proposed MPA boundary delineation and regulatory intent process}

The review of DFO documents allowed identifying different stages in the proposed MPA boundaries, as well as documenting the reasons that motivated those changes. The LC MPA went through five stages of boundary delineation revision during its design, starting from the original EBSA identified by DFO Science, and leading to the final MPA design (Fig. 2). Those progressive reductions in the MPA size resulted in a final MPA $33.4 \%$ smaller when compared to the original EBSA it was based upon (Fig. 3a). The different documents consulted in this study indicate that changes to the boundaries were motivated by the desire to avoid jurisdictional problems with other countries (i.e., avoid French territorial waters to the east), other Canadian provinces (e.g., NL/Nova Scotia offshore oil and gas tribunal line), and fishing grounds of interest to stakeholders (e.g., crab, redfish) (Fig. 3b). Boundary changes resulting from those negotiations with the fisheries industry helped gain the
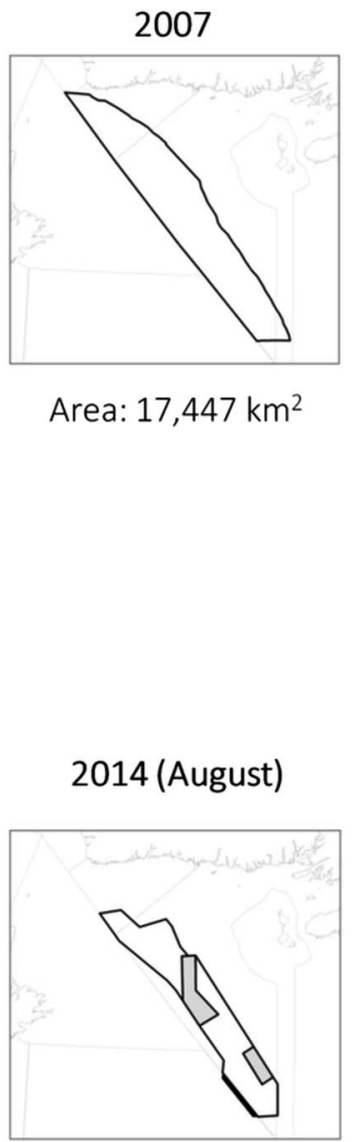

Area: $11,619 \mathrm{~km}^{2}$

Area loss: $2.4 \%$

$(33.4 \%)$

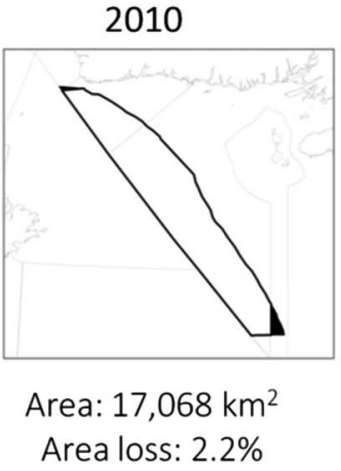

Avoid Nova Scotia oil and border (St.

Pierre and Miquelon EEZ)

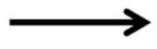

gas regulatory boundary

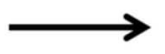

Area loss: $8.9 \%$

(10.9\%)

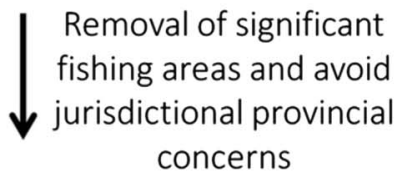

concerns

2014 (April)

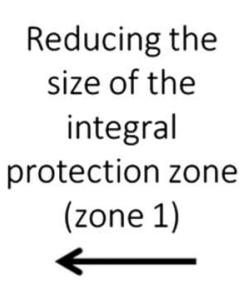

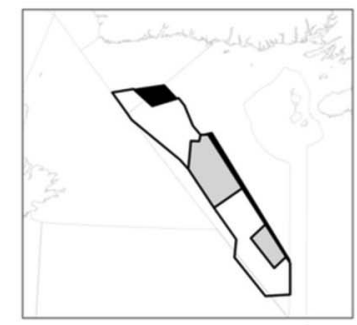

Area: $11,908 \mathrm{~km}^{2}$ Area loss: $7.6 \%$ (31.7\%)

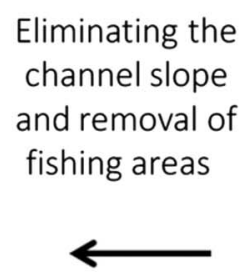

Fig. 2. Stages of the Laurentian Channel marine protected area (MPA) design, from the original ecologically and biologically significant area (EBSA) boundaries (top left) to the proposed MPA (bottom left). Black areas represent areas removed at each stage. Reasons for area removal are indicated at each step, resulting from the analysis of Department of Fisheries and Oceans documents. Dark grey areas reported for 2014 represent the zone with the highest level of protection. Below each stage are indicated the MPA size/area $\left(\mathrm{km}^{2}\right)$, area loss when compared to the previous stage (\%), and cumulative area loss compared to the original EBSA ( $\Sigma$ loss). 
(a)

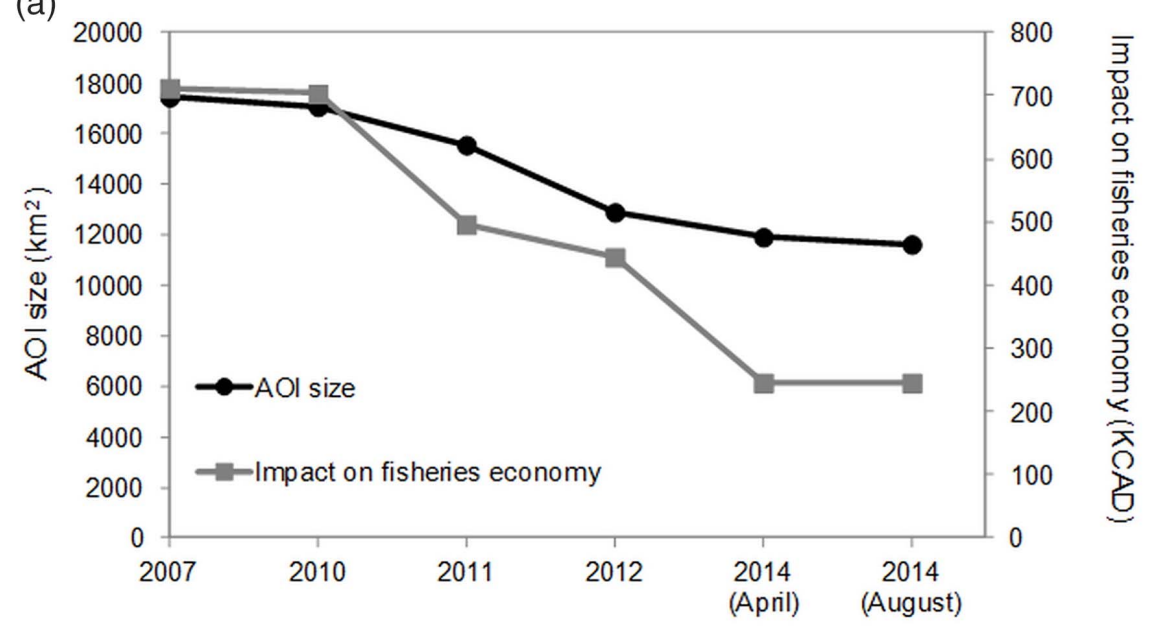

(b)

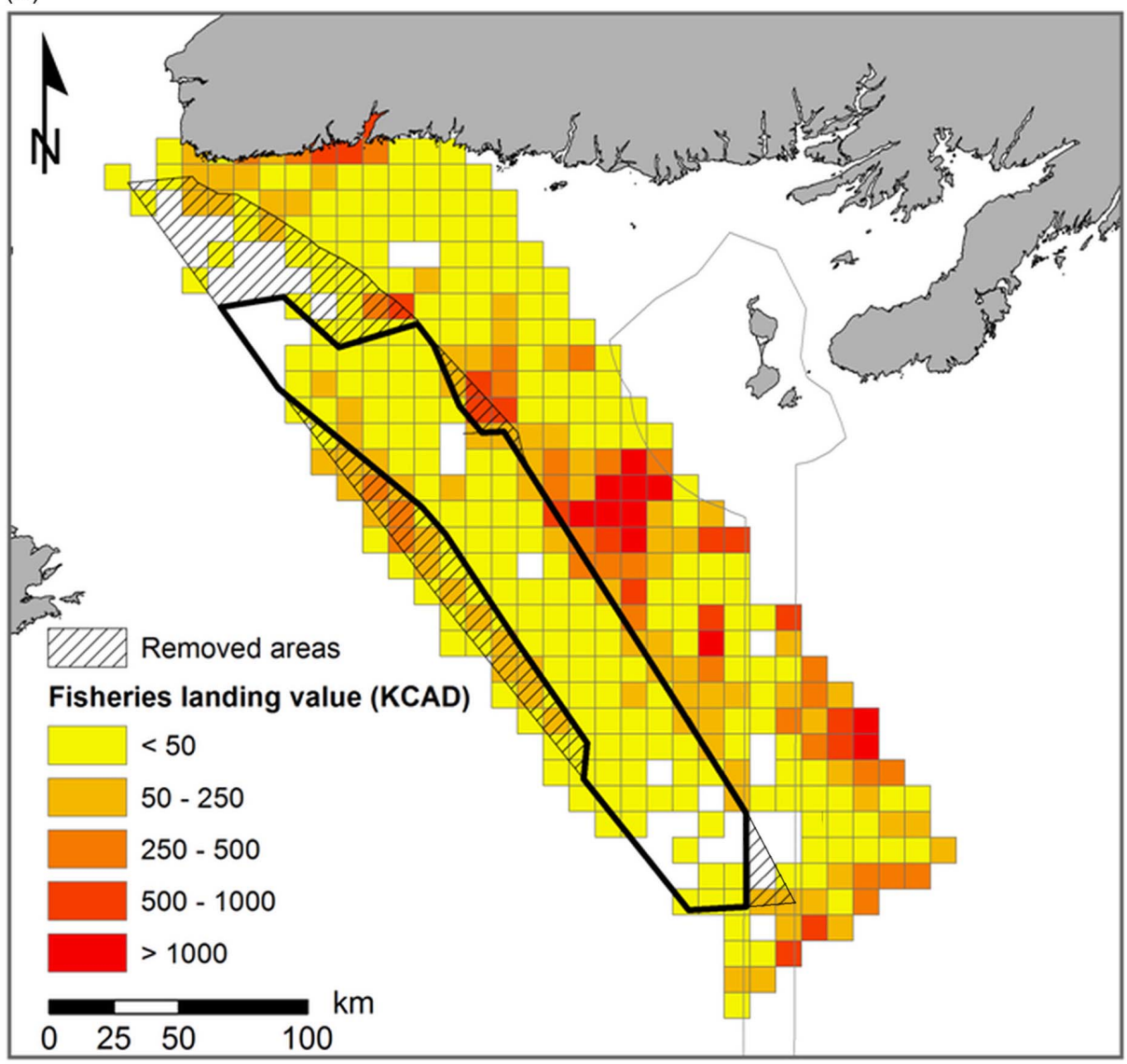

Fig. 3. Changes in the size of the area of interest (AOI, black line) at each stage of the boundary delineation process and estimated mean annual fisheries forgone benefit (grey line, estimation based on the Department of Fisheries and Oceans fisheries nominal landed values data from 2004 to 2013) (a). Average annual fisheries nominal landed values (2004-2013) for the region, with the final marine protected area (MPA) boundaries (thick black line) and areas removed compared to the original ecologically and biologically significant area boundaries (hatches between the thin black line and the MPA boundary line) (b). 
support required to create an MPA that is now closed entirely to industrial fishing. In the final proposed MPA design (August 2014), the impact on fisheries foregone benefits decreased by 65.5\%, going from about CAD $\$ 712000$ per year in potential lost revenues for the initial EBSA boundary, to about CAD $\$ 250000$ for the final MPA boundary.

Despite studies confirming the low potential of the area for oil and gas exploitation (Hannigan and Dietrich 2012; King 2012), government and industry stakeholders involved in the oil and gas sector did not support a complete exclusion of oil and gas activities (Government of Canada 2017), leading to the division of the MPA into two zones (Fig. 1). Zone 1 (18\% of the MPA), designed around areas with higher concentration of sea pens (DFO 2010; Kenchington et al. 2010), was meant to provide the highest level of protection within the MPA. Zone 2 ( $82 \%$ of MPA) was to be a multiple use area allowing anthropogenic activities that are said to be "compatible with the conservation objectives of the MPA" (Government of Canada 2017). Seismic surveys, as well as oil and gas drilling activities, were to be permitted at specific times of the year in Zone 2. Zone 1 was reduced in August 2014 to increase the area accessible by the oil and gas industry, allowing potential drilling from Zone 2 into the seabed located under most of Zone 1 using directional drilling methods (Government of Canada 2017; Watson and Hewson 2018). Strong opposition from scientists, environmental organizations, and citizens in 2018 has, however, led to a complete ban of oil and gas activities in both zones. In its final design, recreational and commercial fishing and oil and gas exploration and exploitation are prohibited in the entire MPA (i.e., both zones). Zone 1 provides additional protection by prohibiting anchoring and laying of submarine cables. Maritime navigation is permitted within the MPA borders.

\section{Potential conservation impacts of boundary changes}

Formal scientific advice was only provided in the initial stages of the MPA establishment process through an initial biophysical overview of the AOI (DFO 2011) and to inform future monitoring of the MPA after the MPA design was finalized (DFO 2014). An advisory committee that included a few government scientists was created to provide advice during the MPA planning process. However, changes to the AOI boundaries and regulatory intent, as well as changes to the conservation objectives, took place without formal peer-reviewed scientific advice that could have required data analyses quantifying the impacts of those changes.

Of 16 species originally identified as candidate conservation priorities based on input from species experts and stakeholders, only six species were included as formal conservation objectives for the AOI following the consultation processes (Table 1). Changes included the removal of species important for the fishing industry that were central in the original AOI recommendation (e.g., cod and redfish). In contrast, sea pens, a group of cold-water corals not explicitly mentioned in the original EBSA study or in the AOI recommendation, emerged during this process to become the flagship species of this proposed MPA as a result of an improved knowledge of the distribution of corals in the region.

Under the overarching MPA goal of aiming to "conserve biodiversity through protection of key species and habitats, ecosystem structure and function, and through scientific research" (DFO 2016), the final conservation objectives were set to protect ( $i$ ) sea pens, (ii) black dogfish, (iii) smooth skate, $(i v)$ porbeagle shark, and $(v)$ northern wolffish from harm and human induced mortality, and to promote the survival and recovery of ( $v i$ ) leatherback sea turtles (Dermochelys coriacea) by minimizing risk of harm from human activities. Most species present in the final list are demersal (fishes) or sessile (sea pens), with the leatherback turtle being the only fully pelagic species.

\section{Trade-offs during the planning process}

Data analyses provided insights on the impacts of boundary changes on the species of conservation priority and on potential economic losses for the fishing industry. When comparing changes in 
species protection level to the three conservation loss scenarios (see Fig. 4), sea pens and smooth skate are found to be above line "a", showing that the reduction in MPA size was proportionally higher than the reduction in protection for those species (i.e., the reduction of $33.4 \%$ in the proposed MPA size led to a smaller percentage of reduction of species' protection). Northern wolffish is close to line "a", whereas black dogfish, cod, and redfish are under this line, indicating that boundary changes resulted in removing areas from the original LC EBSA of higher relative abundance and biomass for those species. The decline in protected abundance (Fig. 4a) was highest for cod (loss of 68.6\% in abundance and $67.7 \%$ in biomass) and redfish (loss of $56.7 \%$ in abundance and $48.3 \%$ in biomass), commercial species excluded in 2012 from the final conservation objectives. The protected abundance for black dogfish decreased by 43\% (Fig. 4a) when compared to the initial EBSA, whereas the biomass (Fig. 4b) within the MPA size decreased by $46 \%$. Porbeagle shark protected biomass decreased by $14.1 \%$.

Most boundary modifications were made at the demand of the fishing industry to help reduce the economic impact on commercial fisheries (Figs. 5a-5c). Spearman correlation analyses indicated statistically significant relationships between the level of protection of species and the potential impact on the fisheries industry (abundance: Spearman $\rho=0.91, p$ value $<0.001$, biomass: Spearman $\rho=0.90, p$ value $<0.001$, species included in conservation objectives only), illustrating the trade-off between the conservation objectives of the MPA, and its potential socio-economic costs. While these costs may be overestimated (i.e., they assume a complete forgone landed value, while some of the fishing effort is likely to be displaced), such data and analysis are often used in conservation planning processes to assess potential forgone benefits of fisheries. Relationships between the level of protection of species and the potential economic loss can help illustrate trade-offs made during an MPA planning process.

\section{Discussion and conclusions}

MPAs are often created at sites of conservation value identified by earlier scientific studies. This was the case for the LC MPA that was selected from a set of candidate sites identified by a scientific process for their ecological and biological significance (i.e., the EBSAs). Such context is also common internationally, as efforts led by the United Nations (UN) in the past decade have aimed at identifying UN EBSAs that can be used as a basis for MPA selection (Dunn et al. 2014). Although conservation science encourages prioritizing the protection of areas facing the highest threats (Margules and Pressey 2000), the LC was instead explicitly selected out other potential EBSA sites for its lower level of human use in an attempt to minimize conflicts with stakeholders, and hence ease the MPA design process. Such an approach is fairly common internationally, described by Devillers et al. (2015) as leading to the creation of "residual MPAs" (i.e., MPAs that are located in areas of low economic interest but often fail to protect areas in more urgent need of protection). While many EBSAs can benefit from the protection provided by an MPA, MPAs may not be the most appropriate management tool to protect species that led to the designation of an EBSAs (e.g., MPAs may be a less appropriate tool to protect some pelagic species). Government documents reviewed do not suggest that the adequacy of this specific management tool for the LC EBSA has played a role in the selection of the LC EBSA out of the other candidate sites.

Our study found that the LC MPA is one-third smaller than the original EBSA identified by science. Size reductions are typical in MPA planning processes in response to socio-economic or political constraints (Pastoors et al. 2000; MPA News 2006). In the LC MPA case, establishing an MPA smaller than the original EBSA can be expected. Many EBSAs are defined as large areas of ecological significance that may not require protecting the entire area, depending on the features and activities occurring within it. The documents analysed do not suggest that changes to the MPA boundaries were motivated by a desire to increase (or maintain) the ecological effectiveness. The impact of reductions 

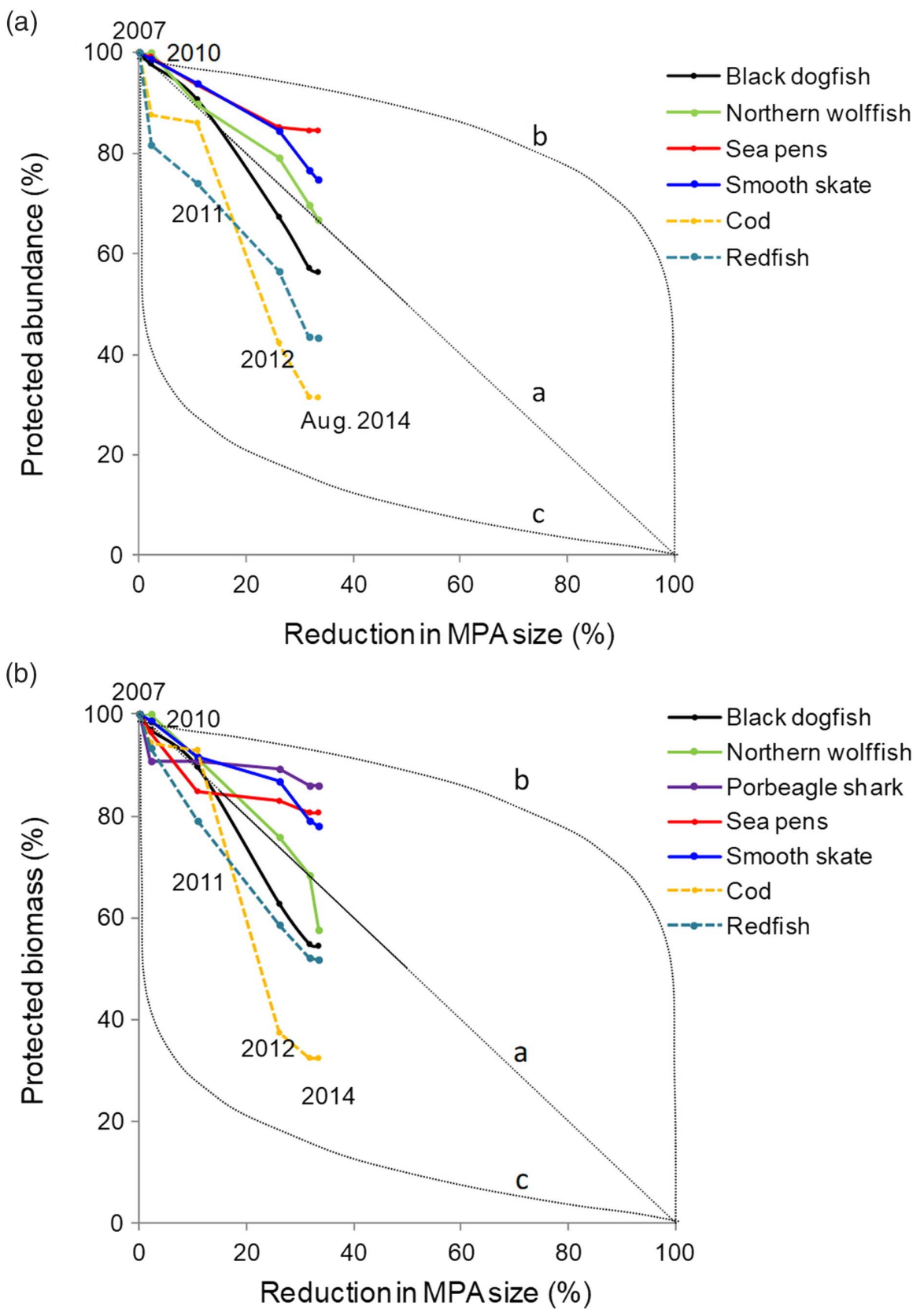

Fig. 4. Percentage of the species abundance (a) and biomass (b) protected by the marine protected area (MPA) at different planning stages, compared with the original ecologically and biologically significant area, as a function of MPA size reduction (normalized values). Solid lines: species included in the conservation objectives. Dashed lines: main commercial species not included as conservation objectives but that had a central role in the original areas of interest recommendation. Each point represents a step in the Laurentian Channel MPA boundaries delineation process (2007-2014). Dotted lines represent different scenarios. Line "a", the "proportional loss" scenario, describes a reduction in size of the MPA that would result in the same proportion of species coverage being left outside the protected area. Line "b", the "marginal loss" scenario (adapted from Tear et al. (2005)), represents the "optimal" relationship for conservation: as size of the MPA is reduced, smaller proportion of protection is lost. An opposite relationship is shown by line " $c$ ", the "unproportional loss" scenario, where small reduction in MPA size can lead to important protection loss. 

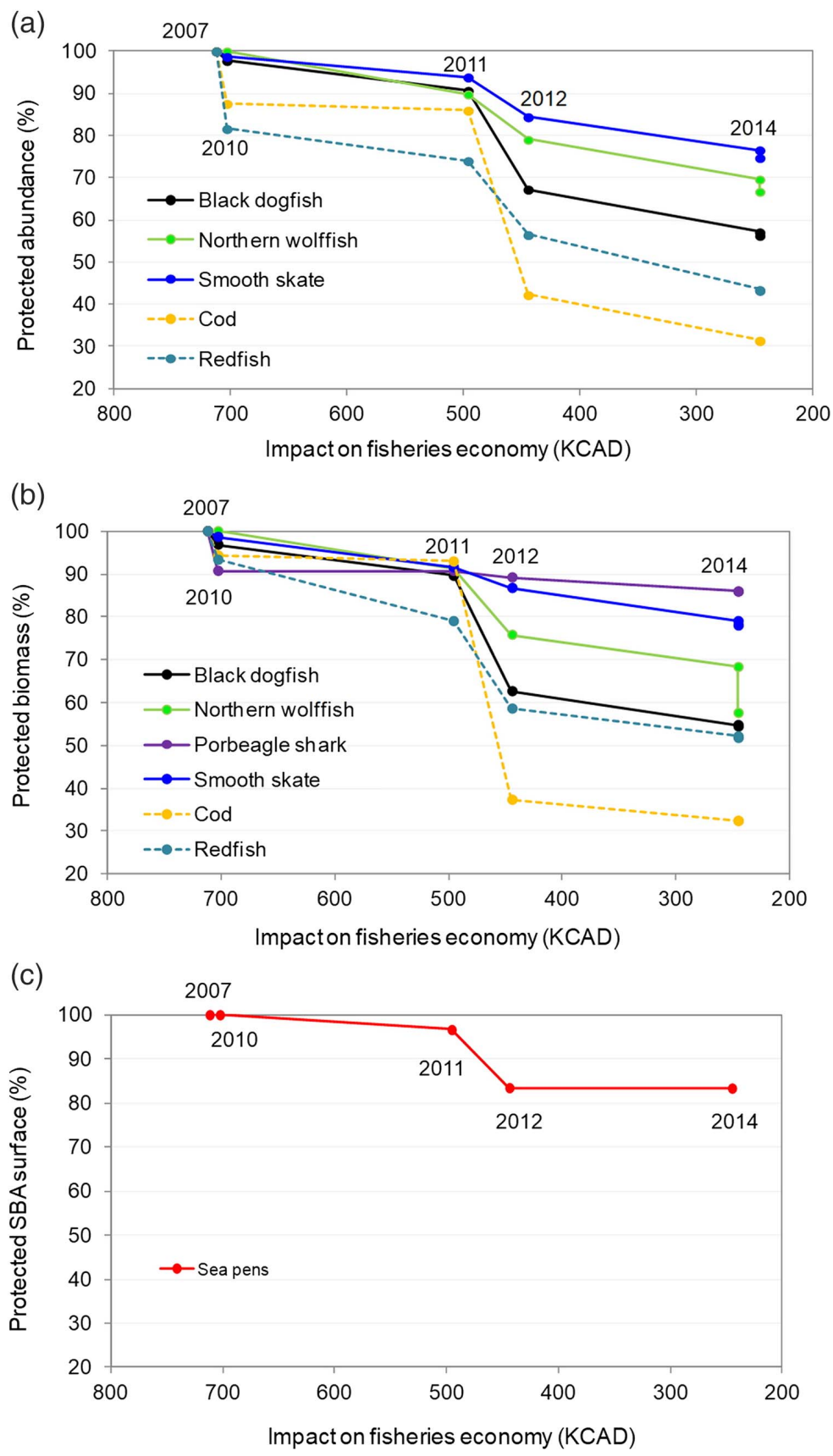

Fig. 5. Percentage of the species abundance (a) and biomass (b) protected by the marine protected area (MPA) at different planning stages, compared with the original ecologically and biologically significant area, in relation to the impact on fisheries economy of the proposed Laurentian Channel MPA (note the reverse order in the $x$-axis). For sea pens (c), protected Significant Benthic Area surface is reported. Solid lines represent the species included as conservation objectives while dashed lines refer to commercial species initially considered as potential conservation targets but removed during the MPA design process. Annual impact on fisheries economy has been estimated based on the landings value for the area during the decade 2004-2013 (Department of Fisheries and Oceans data). It is evident from these figures that the reduction of economic impact is associated with the exclusion of commercial species from the proposed MPA area. 
in size resulting from an MPA planning process on the capacity of the MPA to protect species of interest is however rarely assessed by scientific studies. Such assessment can however be critical to ensure the ecological effectiveness of future MPAs. An ongoing formal scientific assessment of the proposed MPA design criteria (e.g., boundaries, level of protection) throughout the entire process could have helped confirm if the various stages of the proposed MPA still allow for an appropriate protection of the species of conservation priority. The review of the documents indicates that successive changes made to the proposed MPA boundaries and the creation of zones were solely motivated by a desire to accommodate industry users' concerns and done in the absence of any formal scientific advice on the impacts those changes could have on the conservation priorities and the overall MPA ecological effectiveness.

As demonstrated by our analyses, the gradual reduction in size of the MPA has affected some species more than others. The two species that were the most impacted by reduction of the MPA size are cod and redfish, species of commercial interest in this region that were removed from the list of conservation priorities during the process. Those reductions in species abundance and biomass are the direct outcome of the removal of areas that had high concentrations of those two species. Documents also suggest that the removal of those areas important for the fishing industry may have played a role in the decision of dropping these species from the conservation priorities. The abundance and (or) biomass of the five species captured by the final MPA conservation objectives all declined due to the size reduction of the MPA. While some species were less impacted (e.g., porbeagle shark and sea pens, with less of $20 \%$ decline), black dogfish and the biomass of northern wolffish showed declines that are larger than the "proportional loss" scenario (i.e., below line "a" on Fig. 4). Such differences can be explained by the geographic distribution of those species in the region, and their affiliation with specific habitats or substrates. For instance, sea pens that tend to be found on soft sediments in the centre of the LC, areas characterized by smaller fishing effort, were less impacted than some species found in higher abundance on the slope of channel that are better fishing grounds for the industry.

While the future ecological effectiveness of the LC MPA cannot be simply derived from our results, the analytical approach proposed in this paper can be used as a rapid assessment tool by managers and scientists that could prompt more extensive scientific assessments. Species the most impacted by the MPA size reduction could have a higher priority when conducting a formal scientific assessment of the impacts of the proposed changes to the MPA plan. While a reduction of the total area protected can clearly impact the ability of the MPA to protect species, such an impact would not necessarily be detected in a formal assessment of the MPA effectiveness due to the way conservation objectives are worded. Several LC MPA conservation objectives were designed to "protect" species (i.e., corals, black dogfish, smooth skate, and porbeagle sharks). It could be argued that reductions made to the size of the MPA would still ensure a protection of those species, hence resulting in the MPA meeting its objectives, whatever the reduction in size of the MPA is. This highlights the importance of setting conservation objectives that meaningfully reflect and contribute to address the regional conservation challenges as, in this case, meeting the conservation objectives could be very different from protecting effectively the species in this region.

An interesting example of how a paucity of science input can influence MPA design can be illustrated with sea pens in the LC. Now the flagship species of the LC MPA, sea pens were not even listed as a species of interest when the LC EBSA was first selected (Templeman 2007). By the time the LC AOI was formalized in 2010, scientific knowledge had advanced and identified sea pens as important species in the area (DFO 2010; Kenchington et al. 2010), leading to their inclusion among the conservation priorities. The location of sea pen habitats identified in 2010 also led to the delineation of management zones with different protection levels within the MPA (Fig. 6). However, while negotiations with stakeholders led to the MPA zoning and to a size reduction of Zone 1, scientific knowledge 


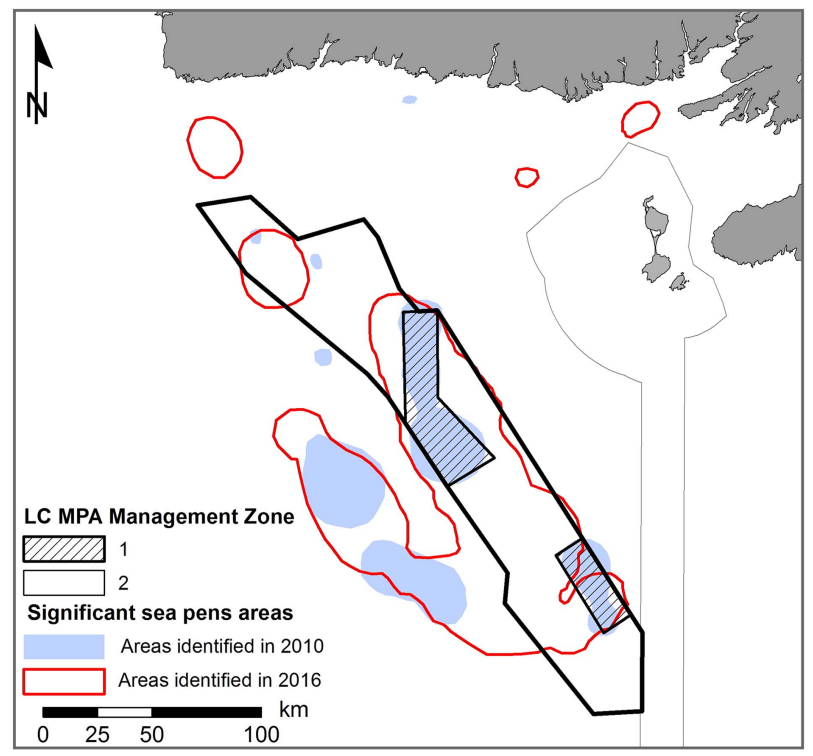

Fig. 6. Comparison of the proposed marine protected area management zones with the location of the significant concentrations of sea pens identified in 2010 (light blue polygons) (DFO 2010; Kenchington et al. 2010) and the sea pen Significant Benthic Areas identified in 2016 (red outline) (Kenchington et al. 2016; DFO 2017).

improved and the most recent science advice (Kenchington et al. 2016; DFO 2017) indicates that most of the LC MPA emerges as a significant sea pen habitat. This may bring to question the current usefulness of the proposed zonation. If lower protection zones were justified by the absence of sea pen habitats, the most recent scientific advice would then suggest that the higher protection zone should have been be vastly expanded to protect other areas of known sea pen presence. Part of this apparent contradiction is associated with the timelines of the decisions, the availability of new scientific studies, and the challenge to integrate new scientific knowledge along the planning process, highlighting issues that could have been identified by formal scientific assessments during the design process and (or) an a posteriori science assessment of the final MPA design. A more regular integration of scientific advice through the entire MPA planning process would help ensure that the MPA design remains appropriate in light of the most recent scientific knowledge. Similarly, a mechanism should exist to update regulations in light of new scientific knowledge during the life of the MPA, something known as adaptive management that has rarely been used in practice for Canadian MPAs (Mills et al. 2015).

The LC case study also raises more general concerns about the way science and stakeholder engagement are incorporated in some MPA design processes. While stakeholder engagement should clearly be an essential component of any MPA design (Kessler 2004; Pomeroy and Douvere 2008), it should be carefully integrated with scientific advice at all stages of the planning process to reduce the risks of establishing "residual reserves" (Devillers et al. 2015). Stakeholders' requests must be carefully implemented in conservation planning to better assess the trade-offs and the impacts that these requests can have on potential conservation effectiveness. As summarized by Klein et al. (2008), a successful MPA design should incorporate stakeholders' interests without compromising biodiversity conservation goals. Such an approach was adopted when revising the Great Barrier Reef MPA network in 2002-2003 by using a systematic conservation planning approach (i.e., using the software tool Marxan). Such an approach ensured that the proposed MPA network design would still meet the quantitative conservation objectives after stakeholders' consultations were conducted 
(Fernandes et al. 2005). Such an approach appears relatively rare in conservation planning, where systematic approaches are more the exception than the rule (McIntosh et al. 2017). Other successful models exist for ensuring that scientific criteria remain central to the MPA planning process. For instance, the creation of a committee called the "Blue Ribbon Task Force" helped ensure that the scientific principles guiding the California State MPA network design were still satisfied once the process was informed by stakeholder groups (Gleason et al. 2013; Kirlin et al. 2013).

Our study provides, to the best of our knowledge, the first quantitative demonstration that integrating stakeholders' interests in MPA planning, when not supported by clear initial quantitative targets or guided along all stages by a formal scientific evaluation, can negatively impact conservation outcomes. Such process can lead to the establishment of residual MPAs (i.e., MPAs are created where there is lower economic interest) and (or) increase the risk of compromising MPAs ecological effectiveness. In the LC case study, it is unclear if the MPA will be effective at protecting black dogfish while $>40 \%$ of this species' abundance and biomass originally covered by the EBSA is now located outside the boundaries of the MPA.

In the LC case, formal science advice by DFO scientists played a limited role during the planning process (2011-2014) (Fig. 7 summarizes some of this process). As far as the available documents indicate (i.e., meeting minutes; see Table S1), the advisory committee provided little advice on changes made to the MPA boundaries and levels of protection, and the scientists involved in the committee were not requested to assess the consequences of such changes on the potential MPA effectiveness, an exercise that would have required formal data analyses conducted by species experts. Our study suggests that many important choices made during the MPA design (e.g., boundary and zoning) seem to have largely responded to socio-economic and political priorities to minimize conflicts with stakeholders and to obtain their support. Such a process potentially jeopardizes how defensible the final proposed MPA is to ensure an effective protection of the species it is being designed to protect. While many studies highlighted the importance of evidence-based decision making in conservation (see Walsh et al. (2014) for an overview or Lemieux et al. (2018) for a discussion in the Canadian context), recent studies pointed out that "decision-makers themselves may not seek or use evidence to make their decisions, even when it is available" (Gardner et al. 2018), an attitude called "evidence complacency" by Sutherland and Wordley (2017). Reasons for such attitude towards evidence can be diverse, but in the context of the LC they could be related to time constraints related to the process, to a perception that additional evidence is not required, or a perception that it will impact the ability to reach an agreement with the stakeholders. A more thorough scientific process used to validate intermediate MPA designs would have required time and resources from DFO Science branch, delayed the progress of the DFO Ocean branch in their planning, but may also have advised against some changes (e.g., exclusion of some areas of importance to the fisheries industry), risking to jeopardize a potential agreement between DFO management and the different stakeholders.

Our study illustrates some of the complex trade-offs that exist in an MPA design process, a challenge discussed in the literature (Halpern et al. 2013), highlights the need for ongoing and formal assessments of the potential MPA effectiveness as the process advances and provides a novel and simple approach to quantify some consequences of those trade-offs (i.e., Fig. 4). The use of a systematic approach to conservation planning similar to what was done for the Great Barrier Reef MPA network could have helped guide the process using clear quantitative conservation targets (e.g., Margules and Pressey 2000), minimizing the risks of compromising the MPA effectiveness. The LC MPA example points to some of the risks of engaging stakeholders in the absence of a continuous scientific supporting process.

When carefully implemented, MPAs were shown to be effective tools supporting the global efforts toward biodiversity conservation. Often, MPAs will restrict industrial activities and lead to lost economic opportunities for different user groups. Clearly, attempting to manage those different and 


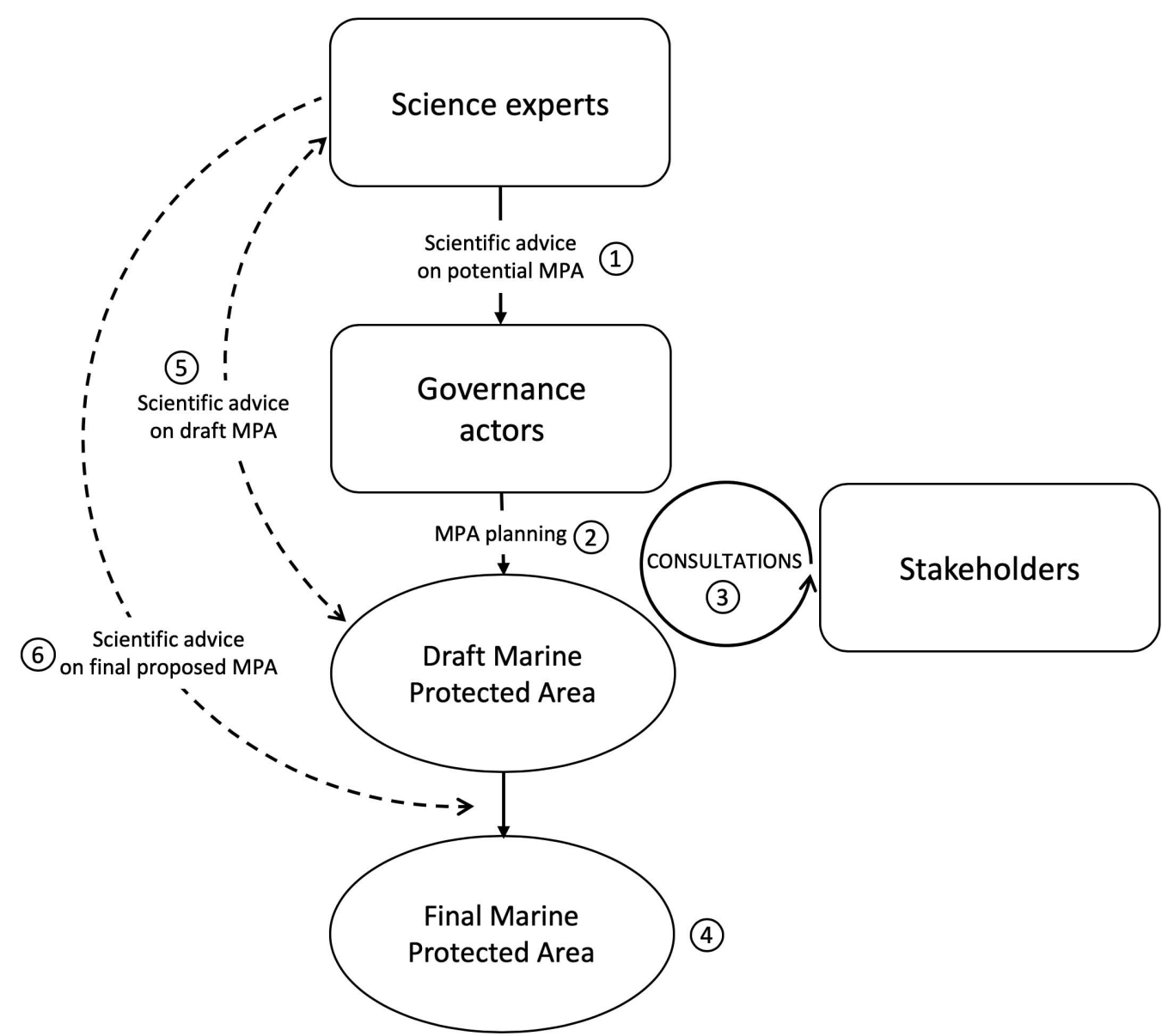

Fig. 7. General marine protected area (MPA) design process followed for the Laurentian Channel (LC) MPA and proposed improvements to the process. (1) Government science experts provided advice on a potential new MPA. (2) Governance actors used this advice to initiate the MPA planning process and proposed MPA designs. (3) Stakeholders were invited to provide input on plans at different stages through the planning through consultations, leading to revised draft MPA designs and ultimately to (4) the final LC MPA design. Findings from our study suggest that formal scientific advice should be required (5) for each revised draft and (6) before the MPA plan are finalized (i.e., dashed lines) to assess if the proposed design still meets the MPA conservation objectives.

at times diverging priorities is essential for minimizing the risks related to the establishment of residuals MPAs. If there is one lesson to be learned from this study, it is that any MPA planning processes should integrate regular scientific advice with stakeholder inputs in a formal and structured way. As the MPA design process develops, this could result in more transparent MPA planning processes that would help ensure the MPA ecological effectiveness, while minimizing its impacts on the different user groups. Doing so would not only prevent potential negative consequences emerging after the MPA has been established, but would also provide a natural mechanism for public engagement and the construction of a broader consensus towards the MPA process.

\section{Acknowledgements}

This study was partly funded by the Natural Sciences and Engineering Research Council (NSERC) of Canada. Thanks are owed to the Department of Fisheries and Oceans Canada (DFO) Newfoundland 
and Labrador for providing biological and socio-economic data, specifically to Nadine Wells, Vonda Wareham, and Mark Simpson. Thanks also to Sigrid Kuehnemund (WWF Canada), three DFO scientists that preferred to remain anonymous, and two other reviewers, for providing feedback on earlier versions of this manuscript.

\section{Author contributions}

$\mathrm{MM}, \mathrm{RD}$, and MKA conceived and designed the study. MM, RD, and MKA performed the experiments/collected the data. MM, RD, and MKA analyzed and interpreted the data. RD and MKA contributed resources. MM, RD, and MKA drafted or revised the manuscript.

\section{Competing interests}

The authors have declared that no competing interests exist.

\section{Data availability statement}

All relevant data are within the paper and in the Supplementary Material.

\section{Supplementary material}

The following Supplementary Material is available with the article through the journal website at doi:10.1139/facets-2018-0033.

Supplementary Material 1

\section{References}

Allison GW, Lubchenko J, and Carr MH. 1998. Marine reserves are necessary but not sufficient for marine conservation. Ecological Application, 8: S79-S92. DOI: 10.2307/2641365

Campana SE, Fowler M, Houlihan D, Joyce W, Showell M, Simpson M, et al. 2015. Recovery potential assessment for porbeagle (Lamna nasus) in Atlantic Canada. DFO Canada, Ottawa, Ontario. 49 pp.

CBD. 2011. Strategic plan for biodiversity 2011-2020. In Conference of the Parties (COP 10) to the Convention on Biological Diversity (CBD), 19-29 December 2010, Nagoya, Japan. 31 pp.

Chess C. 2000. Evaluating environmental public participation: methodological questions. Journal of Environmental Planning and Management, 43: 769-784. DOI: 10.1080/09640560020001674

Chess C, and Purcell K. 1999. Public participation and the environment: do we know what works? Environmental Science and Technology, 33: 2685-2692. DOI: 10.1021/es980500g

Dehens LA, and Fanning LM. 2018. What counts in making marine protected areas (MPAs) count? The role of legitimacy in MPA success in Canada. Ecological Indicators, 86: 45-57. DOI: 10.1016/ j.ecolind.2017.12.026

Devillers R, Pressey RL, Grech A, Kittinger JN, Edgar GJ, Ward T, et al. 2015. Reinventing residual reserves in the sea: are we favouring ease of establishment over need for protection? Aquatic Conservation: Marine and Freshwater Ecosystems, 25: 480-504. DOI: 10.1002/aqc.2445

DFO. 2009. Executive summary of regional AOI recommendation. Fisheries and Oceans Canada, Ottawa, Ontario. 7 pp. 
DFO. 2010. Occurrence, sensitivity to fishing, and ecological function of corals, sponges, and hydrothermal vents in Canadian waters. Fisheries and Oceans Canada, Ottawa, Ontario. 54 pp.

DFO. 2011. Biophysical overview of the Laurentian Channel area of interest (AOI). Fisheries and Oceans Canada, St. John's, Newfoundland and Labrador. 14 pp.

DFO. 2014. Monitoring indicators, protocols and strategies for the proposed Laurentian Channel marine protected area (MPA). Fisheries and Oceans Canada, St. John's, Newfoundland and Labrador. $22 \mathrm{pp}$.

DFO. 2016. Laurentian Channel AOI [online]: Available from dfo-mpo.gc.ca/oceans/aoi-si/ laurentian-laurentien-eng.html.

DFO. 2017. Delineation of significant areas of coldwater corals and sponge-dominated communities in Canada's Atlantic and eastern Arctic marine waters and their overlap with fishing activity. Fisheries and Oceans Canada, Ottawa, Ontario. 45 pp.

Dunn DC, Ardron J, Bax N, Bernal P, Cleary J, Cresswell I, et al. 2014. The Convention on Biological Diversity's Ecologically or Biologically Significant Areas: origins, development, and current status. Marine Policy, 49: 137-145. DOI: 10.1016/j.marpol.2013.12.002

Edgar GJ, Stuart-Smith RD, Willis TJ, Kininmonth S, Baker SC, Banks S, et al. 2014. Global conservation outcomes depend on marine protected areas with five key features. Nature, 506(7487): 216-220. PMID: 24499817 DOI: 10.1038/nature13022

Fernandes L, Day JO, Lewis A, Slegers S, Kerrigan B, Breen DA, et al. 2005. Establishing representative no-take areas in the Great Barrier Reef: large-scale implementation of theory on marine protected areas. Conservation Biology, 19(6): 1733-1744. DOI: 10.1111/j.1523-1739.2005.00302.x

Garcia-Charton JA, Williams ID, Pérez Ruzafa A, Milazzo M, Chemello R, Marcos C, et al. 2000. Evaluating the ecological effects of Mediterranean marine protected areas: habitat, scale and the natural variability of ecosystems. Environmental Conservation, 27: 159-178. DOI: 10.1017/ S0376892900000199

Gardner CJ, Waeber PO, Razafindratsima OH, and Wilmé L. 2018. Decision complacency and conservation planning. Conservation Biology, 32: 1469-1472 [online]: Available from http:// doi.wiley.com/10.1111/cobi.13124. DOI: 10.1111/cobi.13124

Gleason M, Fox E, Ashcraft S, Vasques J, Whiteman E, Serpa P, et al. 2013. Designing a network of marine protected areas in California: achievements, costs, lessons learned, and challenges ahead. Ocean and Coastal Management, 74: 90-101. DOI: 10.1016/j.ocecoaman.2012.08.013

Government of Canada. 2017. Laurentian Channel marine protected area regulations. Canada Gazette, Vol. 151, No. 25, pp. 2740-2768 [online]: Available from gazette.gc.ca/rp-pr/p1/2017/201706-24/html/reg2-eng.php.

Halpern BS, Walbridge S, Selkoe KA, Kappel CV, Micheli F, D’Agrosa C, et al. 2008. A global map of human impact on marine ecosystems. Science, 319: 948-952. PMID: 18276889 DOI: 10.1126/ science. 1149345

Halpern BS, Klein CJ, Brown CJ, Beger M, Grantham HS, Mangubhai S, et al. 2013. Achieving the triple bottom line in the face of inherent trade-offs among social equity, economic return, and 
conservation. Proceedings of the National Academy of Sciences, 110: 6229-6234. PMID: 23530207 DOI: $10.1073 /$ pnas. 1217689110

Hannigan PK, and Dietrich JR. 2012. Petroleum resource potential of the Laurentian Channel area of interest, Atlantic Margin of Canada. Natural Resources Canada, Calgary, Alberta. 36 pp [online]: Available from geoscan.nrcan.gc.ca/starweb/geoscan/servlet.starweb?path=geoscan/fulle.web \& search $1=\mathrm{R}=289846$.

Jameson SC, Tupper MH, and Ridley JM. 2002. The three screen doors: can marine "protected" areas be effective? Marine Pollution Bulletin, 44: 1177-1183. PMID: 12523516 DOI: 10.1016/S0025326X(02)00258-8

Jessen S, Chan K, Côté I, Dearden P, De Santo E, Fortin MJ, et al. 2011. Science-based guidelines for MPAs and MPA networks in Canada. Canadian Parks and Wilderness Society. Vancouver, British Columbia. 58 pp.

Johnson CN, Balmford A., Brook BW, Buettel JC, Galetto M, Guangchum L, et al. 2017. Biodiversity losses and conservation responses in the Anthropocene. Science, 356(6335): 270-275. PMID: 28428393 DOI: $10.1126 /$ science.aam9317

Kenchington E, Lirette C, Cogswell A, Archambault D, Archambault P, Benoît HP, et al. 2010. Delineating coral and sponge concentrations in the biogeographic regions of the East Coast of Canada using spatial analyses. Fisheries and Oceans Canada Canadian Science Advisory Secretariat Research Document 1919-50442010/041. Fisheries and Oceans Canada, Dartmouth, Nova Scotia. $202 \mathrm{pp}$.

Kenchington E, Beazley L, Lirette C, Murillo FJ, Guijarro J, Wareham V, et al. 2016. Delineation of coral and sponge significant benthic areas in Eastern Canada using kernel density analyses and species distribution models. Fisheries and Oceans Canada Research Document 2016/093. Fisheries and Oceans Canada, Ottawa, Ontario. 184 pp.

Kessler BL. 2004. Stakeholder participation: a synthesis of current literature. National Marine Protected Areas Center, Silver Spring, Maryland [online]: Available from https://nmsmarineprotectedareas. blob.core.windows.net/marineprotectedareas-prod/media/archive/pdf/publications/Stakeholder_ Synthesis.pdf.

King EL. 2012. Mineral resource assessment of the shallowest bedrock and overburden, Laurentian Channel, Newfoundland: potential marine protected area. Natural Resources Canada, Dartmouth, Nova Scotia. 27 pp.

Kirlin J, Caldwell M, Gleason M, Weber M, Ugoretz J, Fox E, et al. 2013. California’s Marine Life Protection Act Initiative: supporting implementation of legislation establishing a statewide network of marine protected areas. Ocean and Coastal Management, 74: 3-13. DOI: 10.1016/ j.ocecoaman.2012.08.015

Klein CJ, Chan A, Kircher L, Cundiff AJ, Gardner N, Hrovat Y, et al. 2008. Striking a balance between biodiversity conservation and socioeconomic viability in the design of Marine Protected Areas. Conservation Biology, 22: 691-700. PMID: 18325043 DOI: 10.1111/j.1523-1739.2008.00896.x

Lemieux CJ, Groulx MW, Bocking S, and Beechey TJ. 2018. Evidence-based decision-making in Canada's protected areas organizations: implications for management effectiveness. FACETS, 3: 
392-414 [online]: Available from http://www.facetsjournal.com/doi/10.1139/facets-2017-0107. DOI: 10.1139/facets-2017-0107

Leslie HM, and McLeod KL. 2007. Confronting the challenges of implementing marine ecosystembased management. Frontiers in Ecology and the Environment, 5: 540-548. DOI: 10.1890/060093

Margules CR, and Pressey RL. 2000. Systematic conservation planning. Nature, 405: 243-253. PMID: 10821285 DOI: $10.1038 / 35012251$

Mascia MB. 2003. The human dimension of coral reef marine protected areas: recent social science research and its policy implications. Conservation Biology, 17: 630-632. DOI: 10.1046/j.15231739.2003.01454.x

McCallum BR, and Walsh SJ. 1997. Groundfish survey trawls used at the Northwest Atlantic Fisheries Centre, 1971 to present. NAFO Scientific Council Studies No. 29. pp. 93-104.

McIntosh EJ, Pressey RL, Lloyd S, Smith RJ, and Grenyer R. 2017. The impact of systematic conservation planning. Annual Review of Environment and Resources, 42: 677-697. DOI: 10.1146/annurevenviron-102016-060902

Mills M, Weeks R, Pressey RL, Gleason MG, Eisma-Osorio RL, Lombard AT, et al. 2015. Real-world progress in overcoming the challenges of adaptive spatial planning in marine protected areas. Biological Conservation, 181: 54-63. DOI: 10.1016/j.biocon.2014.10.028

Minister of Justice of Canada. 1997. Oceans Act (S.C. 1996, c. 31). 32 pp [online]: Available from laws-lois.justice.gc.ca/eng/acts/O-2.4/.

MPA News. 2006. Balancing ecology and economics: viewpoints on the process of planning an MPA network for SE Australia. MPA News, Vol. 7, No. 7 [online]: Available from mpanews.openchannels.org/news/mpa-news/balancing-ecology-and-economics-viewpoints-processplanning-mpa-network-se-australia.

NAFO. 2013. NAFO research vessel stock-by-stock surveys summary 2000-2010. NAFO Scientific Council Studies 45. Northwest Atlantic Fisheries Organization, Dartmouth, Nova Scotia. pp. 1-91. DOI: $10.2960 /$ S.v $45 . \mathrm{m} 1$

Oracion EG, Miller ML, and Christie P. 2005. Marine protected areas for whom? Fisheries, tourism, and solidarity in a Philippine community. Ocean and Coastal Management, 48: 393-410. DOI: 10.1016/j.ocecoaman.2005.04.013

Pastoors MA, Rijnsdorp AD, and Van Beck FA. 2000. Effects of a partially closed area in the North Sea ("plaice box") on stock development of plaice. ICES Journal of Marine Science, 57: 1014-1022. DOI: $10.1006 /$ jmsc. 2000.0586

Pomeroy R, and Douvere F. 2008. The engagement of stakeholders in the marine spatial planning process. Marine Policy, 32: 816-822. DOI: 10.1016/j.marpol.2008.03.017

Ruiz-Frau A, Possingham HP, Edwards-Jones G, Klein CJ, Segan D, and Kaiser MJ. 2015. A multidisciplinary approach in the design of marine protected areas: integration of science and stakeholder based methods. Ocean and Coastal Management, 103: 86-93. DOI: 10.1016/j.ocecoaman.2014.11.012

Sutherland WJ, and Wordley CFR. 2017. Evidence complacency hampers conservation. Nature Ecology and Evolution, 1: 1215-1216. PMID: 29046534 DOI: 10.1038/s41559-017-0244-1 
Tear TH, Kareiva P, Angermeier PL, Comer P, Czech B, Kautz R, et al. 2005. How much is enough? The recurrent problem of setting measurable objectives in conservation. BioScience, 55: 835-49. DOI: 10.1641/0006-3568(2005)055[0835:HMIETR]2.0.CO;2

Templeman N. 2007. Placentia Bay-Grand Banks large ocean management area ecologically and biologically significant areas. DFO Canada, St. John's, Newfoundland and Labrador. 15 pp.

Walsh JC, Dicks LV, and Sutherland WJ. 2014. The effect of scientific evidence on conservation practitioners' management decisions. Conservation Biology, 29: 88-98. PMID: 25103469 DOI: 10.1111/cobi.12370

Watson MS, and Hewson SM. 2018. Securing protection standards for Canada's marine protected areas. Marine Policy, 95: 117-122. DOI: 10.1016/j.marpol.2018.07.002 